\title{
'Bronchitis' in patients with mitral stenosis
}

\author{
C L I VE P. A B ER \\ From the Liverpool Royal Infirmary
}

Episodes of 'recurrent bronchitis' following minor upper respiratory tract infections are common in patients with mitral stenosis. The first incident of this type is often found in retrospect to mark the onset of progressive deterioration in exercise tolerance.

The clinical features of 'bronchitis' in these patients, however, frequently differ from those of true purulent bronchitis. There may be little, if any, infection of the sputum, and pyrexia is either absent or unimpressive. Orthopnoea is commonly present, and the response to routine therapy with antibiotics and bronchodilator drugs is slow and incomplete, leaving a wheezy chest for several weeks. On the other hand, there is no doubt that purulent bronchitis and emphysema do occur in patients with mitral stenosis.

It is of the utmost importance, therefore, when assessing patients for mitral valvotomy to be able to separate these two groups since it is essential to know how much respiratory disability is due to the pulmonary consequences of mitral valve obstruction and how much is caused by true bronchitis and/or emphysema. In this way, both the operative risks and the likelihood of being able to provide maximum benefit from this type of operation can be assessed more accurately. Similarly, physiological information that separates these two groups of 'bronchitic cardiac patients' can guide the post-operative management of patients in the true bronchitic and emphysematous group where elective tracheostomy and/or assisted ventilation may save a life (Temple, 1961).

The present investigation was designed to compare the pulmonary function of patients with mitral stenosis who had experienced recurrent bronchitis with that of patients with mitral stenosis who had never experienced symptoms of this nature.

\section{MATERIAL AND METHODS}

Included in this study were 84 patients, 69 women and 15 men, with dominant mitral stenosis, who all subsequently had a mitral valvotomy.

Each patient was placed in one of five grades ( 0 to IV) according to the pre-operative functional incapacity, using the New York Heart Associationf Classification (1945). On this basis, there were not patients in grade 0 ; five patients, two men and three women, in grade $I ; 38$ patients, six men and 3200 women, in grade II ; 35 patients, four men and $3 \mathrm{~L}$ women, in grade III ; and six patients, one man andr five women, in grade IV.

Thirty-eight of the 84 patients $(45.2 \%)$ gave $\frac{\circ}{2}$ history of recurrent bronchitis for at least two years before admission to hospital, 24 for over five years and eight for 10 years or more. Twenty-six has wheezy chests at the time this investigation was performed.

No patient with a history of primary respirator@ disease was admitted to this series and none had either clinical or radiological evidence of emphysemas

METHODS The following lung function tests were carried out on the patients at rest in the sitting position. The vital capacity (V.C.), the forced expirab tory volume over one second (F.E.V., ), the maximur? inspiratory and expiratory flow rates (M.I.F.R. an $\overrightarrow{6}$ M.E.F.R.), and the maximum voluntary ventilation (M.V.V.80) were measured, using a low resistance spirometer (Bernstein, D'Silva, and Mendel, 1952). I⿳亠丷⿵冂⿱十口. 28 patients, 17 bronchitic and 11 non-bronchitic, these spirometric measurements were repeated after the subcutaneous administration of a bronchodilator drugi adrenaline hydrochloride, $0.3 \mathrm{mg}$.

The residual volume (R.V.) was determined by closed-circuit helium dilution method (Weiner ang Cooper, 1956). The intrapulmonary (alveolar) mixing efficiency (M.E.\%) was then calculated (Bates and Christie, 1950).

Predicted normal values for the lung volumes maximum voluntary ventilation, and intrapulmonar mixing efficiency were calculated from the simplifie regression formulae of Needham, Rogan, and McDonald (1954).

In 63 patients direct mean left atrial and pulmonar artery pressures were obtained at thoracotomy through a 21-gauge needle connected with a saline manomete by a metre of hardened nylon tubing of $1.5 \mathrm{~mm}$. bore

\section{RESULTS}

Neither sex nor age seemed to influence the incidence of recurrent bronchitis in any grade of functional incapacity. The greater the disabilit禺 however, the more likely were such symptoms to be present (Table I). 
TABLE I

THE INCIDENCE OF RECURRENT BRONCHITIS RELATIVE TO FUNCTIONAL INCAPACITY IN 84 PATIENTS WITH MITRAL STENOSIS

\begin{tabular}{lccccc}
$\begin{array}{l}\text { Functional } \\
\text { Status }\end{array}$ & $\begin{array}{l}\text { Non-bronchitic } \\
\text { Patients }\end{array}$ & \multicolumn{2}{l}{$\begin{array}{l}\text { Bronchitic } \\
\text { Patients }\end{array}$} \\
\cline { 2 - 5 } \cline { 5 - 6 } & No. & $\%$ & & No. & $\%$ \\
\hline Group I & 5 & 100 & 0 & 0 \\
Group II & 23 & 60.5 & 15 & $39 \cdot 5$ \\
Group III & 17 & 48.6 & 18 & $51 \cdot 4$ \\
Group IV & 2 & 33.3 & 4 & 66.6
\end{tabular}

LUNG VOLUMES The residual volume was raised to $120 \%$ or more of the predicted normal value in 16 patients, only six of whom were in the bronchitic group. Similarly, the expiratory reserve volume was significantly increased in 22 patients, seven of whom were bronchitic.

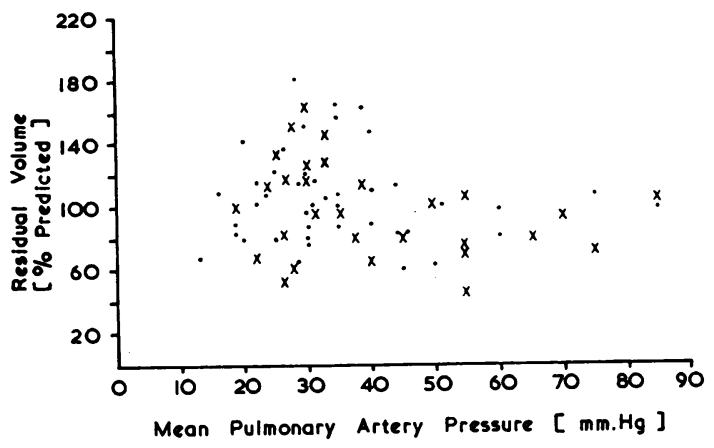

FIG. 1
At all levels of mean pulmonary artery and left atrial pressures the residual volume and expiratory reserve volume were similar in both groups (Figs. 1 to 4). However, the residual volume was never significantly increased when the mean pulmonary artery pressure was less than $20 \mathrm{~mm}$. $\mathrm{Hg}$ or greater than $40 \mathrm{~mm}$. $\mathrm{Hg}$ (Fig. 1). A similar relationship was observed, with one exception, between the expiratory reserve volume and the mean pulmonary artery pressure (Fig. 3).

The ratio of the residual volume to the total lung capacity (T.L.C.) was similar for both groups of patients with grade II and grade III functional incapacity, but this ratio was higher in the nonbronchitic patients in grade IV (Table II).

VENTILATORY CAPACITY The non-bronchitic and bronchitic patients in each grade of functional

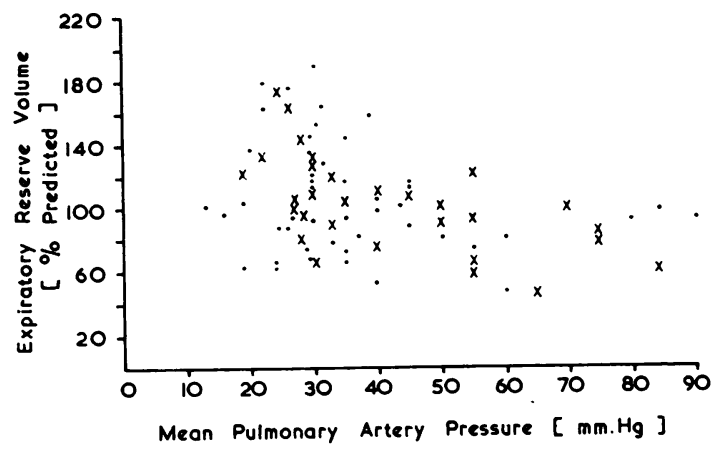

FIG. 3

FIG. 1. The relationship of the residual volume to the mean pulmonary artery pressure in patients with mitral stenosis. FIG. 3. The relationship of the expiratory reserve volume to the mean pulmonary artery pressure in patients with mitral stenosis.

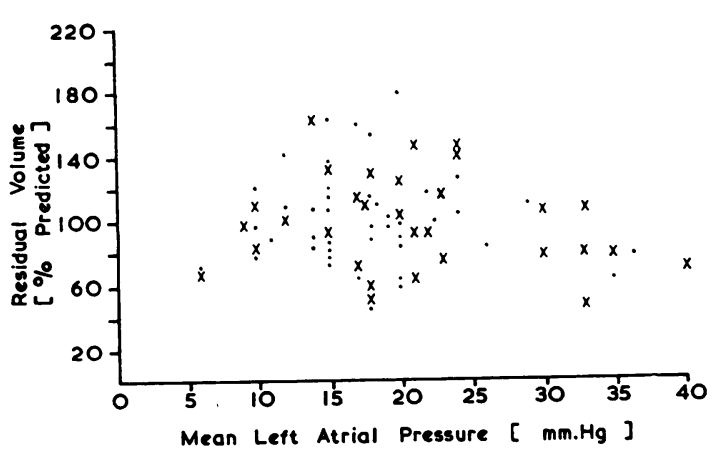

FIG. 2

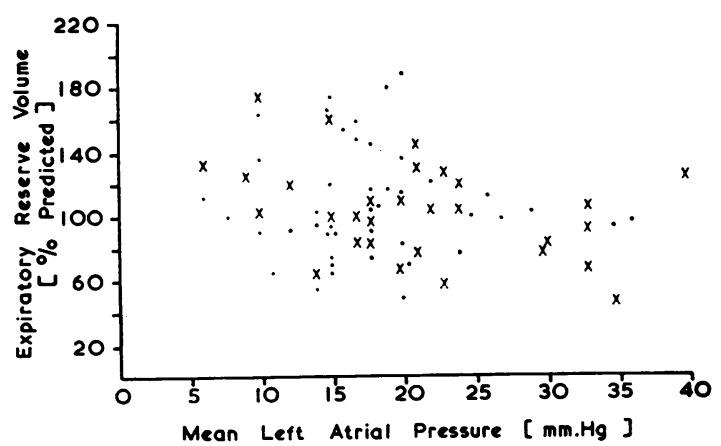

FIG. 4

FIG. 2. The relationship of the residual volume to the mean left atrial pressure in patients with mitral stenosis.

FIG. 4. The relationship of the expiratory reserve volume to the mean left atrial pressure in patients with mitral stenosis.

$$
\bullet=\text { inon-bronchitic patient. } \mathrm{x}=\text { bronchitic patient. }
$$


TABLE II

VENTILATORY CAPACITY OF NON-BRONCHITIC AND BRONCHITIC PATIENTS WITH MITRAL STENOSIS RELATIVE TO FUNCTIONAL INCAPACITY

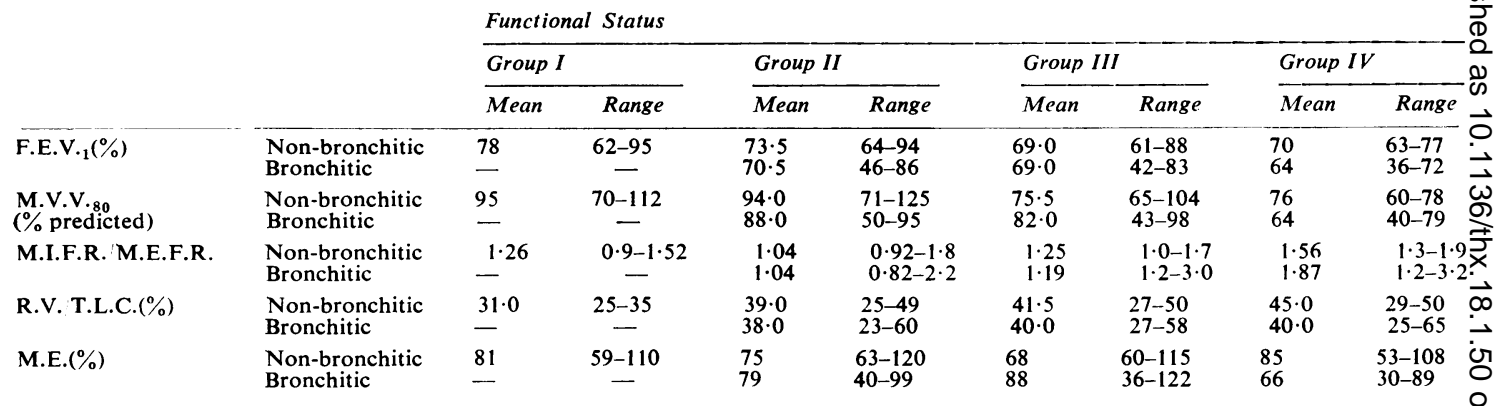

incapacity had very similar mean indices of ventilatory capacity (Table II). Five of the bronchitic group, two men and three women, however, showed evidence of an appreciable degree of obstructive pulmonary disease; one patient was from grade II, two patients from grade III, and two patients from grade IV (Table III).

The response to the subcutaneous administration of a bronchodilator drug was similar in both groups, being variab'e and unpredictable. Thus, whereas in some patients there appeared to be 3 a significant improvement in the maximum voluntary ventilation, this type of response was $\supset$ inconstant, and, when present, was not usually $\vec{\bullet}$ associated with improvement in the other indicesक of ventilatory capacity except in one instance (no. 49, Table IV). This patient later admitted to having had attacks of 'bronchial asthma' from $7 \stackrel{\overline{0}}{3}$ to 10 years of age but she had been free fromo

TABLE III

VENTILATORY CAPACITY OF PATIENTS WITH UNCOMPLICATED MITRAL STENOSIS, RECURRENT BRONCHITIS ANDŌ̄ MITRAL STENOSIS, AND OBSTRUCTIVE PULMONARY DISEASE AND MITRAL STENOSIS

$$
\text { F.E.V. }{ }_{1}(\%)
$$

Mitral stenosis (46 patients)

Bronchitic mitral stenosis (33 patients)

Mitral stenosis with obstructive pulmonary

disease ( 5 patients)

72

42
M.V.V.80 (\% Predicted)

M.I.F.R. M.E.F.R. R.V.T.L.C.

74

70

$1 \cdot 2$
$1 \cdot 3$

$2 \cdot 8$

46

T ABLE I V

VENTILATORY RESPONSE OF NON-BRONCHITIC AND BRONCHITIC PATIENTS WITH MITR LL SIENOSIS TO 0.3 MG. ADRENALINEO HYDROCHLORIDE

\begin{tabular}{lccr}
$\begin{array}{l}\text { Functional } \\
\text { Status }\end{array}$ & \multicolumn{2}{c}{ Non-bronchitic Patients } & \\
\cline { 2 - 4 } & $\begin{array}{l}\text { Increase in } \\
\text { M.V.V.80 } \\
\% \text { Normal })\end{array}$ & $\begin{array}{l}\text { Change in } \\
\text { M.I.F.R. M.E.F.R. } \\
\text { Ratio }\end{array}$ & $\begin{array}{l}\text { Change } \\
\text { F.E.V. } \% \\
\% \text { Norm }\end{array}$ \\
\hline Group I & 0 & -0.16 & -5 \\
Group II & 11 & -0.12 & +2 \\
& 6 & -0.07 & +5 \\
& 10 & 0 & -2 \\
Group III & 3 & -0.05 & +2 \\
& 33 & -0.13 & -7 \\
& 15 & -0.16 & +9 \\
& 7 & +0.06 & -7 \\
& 0 & -0.07 & +4 \\
& 41 & -0.05 & +2
\end{tabular}

Group IV

$\begin{array}{ccc}-5 & & \\ +2 & & \\ +5 & 9 & +0.14 \\ & 24 & +0.11 \\ -2 & 29 & -0.32 \\ +2 & 0 & 0 \\ & 5 & -0.07 \\ -7 & 28 & 0 \\ +9 & 14 & -0.21 \\ -7 & 30(\text { No. } 49) & -1.02 \\ +2 & 11 & +0.08 \\ -4 & 40 & 0.01 \\ +2 & 12 & +0 \cdot 38 \\ & 19 & +0.81 \\ & 13 & +0.37 \\ & 40 & +0.10 \\ & 15 & +0.09 \\ & 28 & +0.07 \\ & 37 & -0.57\end{array}$


respiratory symptoms for 25 years before the onset of the heart trouble.

MIXING EFFICIENCY A significant disturbance of gaseous mixing was shown in seven patients, five of whom had evidence of appreciable obstructive pulmonary disease (Tables II and III).

POST-VALVotomy MANAGEMENT An elective tracheostomy was performed after completion of the valvotomy on the five patients who had evidence of obstructive pulmonary disease. Four of them subsequently required assisted ventilation for periods varying from 12 to 72 hours. All these patients had an appreciable degree of mitral stenosis (valve diameter $1.5 \mathrm{~cm}$. or less) and subsequently gained considerable benefit from the operation.

\section{DISCUSSION}

Although no comparable study has previously been made, the present results confirm observations made by several other workers that in patients with mitral stenosis there is usually no evidence of a significant degree of airway obstruction despite the presence of a wheezy chest on auscultation (Carroll, Cohn, and Riley, 1953; Clowes, Hackel, Mueller, and Gillespie, 1953; Curti, Cohen, Castleman, Scannell, Friedlich, and Myers, 1953; West, Bliss, Wood, and Richards, 1953 ; Friedman, Macias, and $\mathrm{Yu}, 1959)$. It is not clear why these patients should have wheezy chests and complain of frequent recurrent bronchitis following minor upper respiratory tract infections. Such infective episodes probably provoke congestive oedema of the bronchial mucosa but fail to produce permanent structural damage in the bronchial walls or emphysema in the distal lung tissue. The disappearance of respiratory incidents of this nature after successful mitral valvotomy tends to support this concept.

Occasionally, however, simple pulmonary function tests, such as F.E.V., \%, M.I.F.R./ M.E.F.R., and M.V.V. ${ }_{80}$, reveal a significant degree of airway obstruction in the bronchitic group. If mitral valvotomy is attempted in such patients, in an endeavour to achieve worth-while, albeit incomplete, symptomatic improvement, elective tracheostomy is advisable. Assisted ventilation can then be commenced, if required, with a minimum of inconvenience to both patient and staff.

The reason for the observed increase in maximum voluntary ventilation after the administration of adrenaline hydrochloride in both the non-bronchitic and bronchitic patients in this series is not known. It may have been due to the non-specific psychological and physical boostering effect of this drug.

Finally, it should be appreciated that in uncomplicated mitral stenosis the residual volume is commonly raised when the mean pulmonary artery pressure is between 20 and $40 \mathrm{~mm}$. $\mathrm{Hg}$. This disturbance of pulmonary function might otherwise erroneously suggest the presence of emphysema in a wheezy and bronchitic patient. However, the associated findings of an increased expiratory reserve volume under such circumstances and a lack of evidence of airway obstruction should prevent this mistake from being made.

\section{SUMMARY}

Pulmonary function studies were performed on 46 patients with uncomplicated mitral stenosis and on 38 patients with mitral stenosis who had experienced recurrent bronchitis for more than two years before mitral valvotomy.

There was no objective evidence of obstructive pulmonary disease in most of these patients despite wheezy chests in $71 \%$ of the bronchitic group and frequent elevation of the residual volume in both groups.

Simple spirometric measurements of F.E.V. $\%$, M.I.F.R./M.E.F.R., and M.V.V. ${ }_{80}$ revealed a significant degree of airway obstruction in only five of the bronchitic patients. Elective tracheostomy was performed on these patients, four of whom also required assisted ventilation in the post-operative period.

I should like to thank Mr. Ronald Edwards, Mr. John Bickford, Mr. Leslie Temple, Mr. K. Waddington, Dr. E. N. Chamberlain, Dr. E. Wyn Jones, Dr. C. S. McKendrick, and Dr. Norman Coulshed for allowing me access to their patients.

My thanks are also due to Dr. W. S. Sutton and Dr. C. Ogilvie for their encouragement and advice whilst performing this work.

\section{REFERENCES}

Bates, D. V., and Christie, R. V. (1950). Clin. Sci., 9, 17.

Bernstein, L., D'Silva, J. L., and Mendel, D. (1952). Thorax, 7, 255.

Carroll, D., Cohn, J. E., and Riley, R. L. (1953). J. clin. Invest., 32, 510.

Clowes, G. H. A., Hackel, D. B., Mueller, R. P., and Gillespie, D. G. (1953). A.M.A. Arch. Surg., 67, 244.

Curti, P. C., Cohen, G., Castleman, B., Scannell, J. G., Friedlich, A. L., and Myers, G. S. (1953). Circulation, 8, 893.

Friedman, B. L., Macias, J. de J., and Yu, P. N. (1959). Amer. Rev. Tuberc., 79, 265.

Needham, C. D., Rogan, M. C., and McDonald, I. (1954). Thorax, 9, 313.

Temple, L. J. T. (1961). Personal communication.

Weiner, R. S., and Cooper, P. (1956). Amer. Rev. Tuberc., 74, 729.

West, J. R., Bliss, H. A., Wood, J. A., and Richards, D. W. (1953). Ci 'culation, 8, 178. 